\title{
Physician-scientist, heal thyself . . .
}

\begin{abstract}
Historically, physician-scientists have had dual roles in caring for patients and in performing investigative research that could potentially lead to new diagnostics and therapeutics. Physician-scientists conducted teaching rounds in the hospital, surrounded by eager house staff and medical students, and were often avidly pursued as the most important sources of new knowledge for trainees. But alas, times have changed. Now physicianscientists are rarely seen in the hospital; they are most often spotted at their desks tapping out yet another grant application. Most struggle to find the time to mentor students and clinical trainees, let alone to care for patients in the hospital, even though these interactions are often the motivating forces for scientific creativity.
\end{abstract}

I recently made an enlightening back-ofthe-envelope calculation that showed I may actually spend more hours per year at mandated training courses on hand washing, Medicare/Medicaid billing, record keeping, etc. than I do seeing patients in the approximately one month each year when I serve as an attending physician. Administrative details have piled up, necessitating more committees, training sessions, and meetings than ever before.

When I first began my career as a physician-scientist at Harvard, two-thirds of my salary was paid from an American Heart Association grant, and $\$ 15,000$ was paid by the hospital. The three months I spent reading electrocardiograms and attending to patients more than merited this compensation and represented a nice profit for the Department of Medicine. Now, given the myriad costs associated with running a hospital, there is no possibility that a parttime clinician like myself could end up helping the bottom line. Then there is malpractice insurance. It used to be prorated at our hospital; now it is not. As a noninterventional cardiologist, I pay $\$ 10,000$ for one year of coverage. That would be a bargain if I got paid to see patients. However, since I receive no compensation for patient care and the department receives little if any income from my clinical activities, the economic model that worked nicely in the past no longer applies.

Administrative demands deplete our time and effort and prevent us from meaningful participation in patient care and clinical teaching. As an example, although physician-scientists are becoming a rare breed, deans still need us on committees to represent faculty of national and international stature, so each of us has to serve on numerous committees. Additionally, given the current state of the NIH most grants require multiple rewrites even if they are funded, so the amount of time spent writing grants has grown exponentially. This all puts a time-consuming burden on researchers, and physician-scientists often have primary affiliations in clinical departments without adequate research infrastructure or administrative support for research.

Moreover, given increasing competition for limited resources from the NIH, physician-scientists must publish in the top journals to have any chance of running a successful, funded research program. The days of the "gentleman physician-scientist," when one could make contributions and have a part-time career in research, are over. Nevertheless, meaningful research collaborations can be developed to allow for genuine give and take between basic science and clinical faculty (1).

We need creative approaches to enhancing the role of physician-scientists in academic health centers. One area to reform is teaching rounds. In academic health centers, teaching rounds are designed to provide optimal patient care as well as to create opportunities to study diseases and to help devise novel cures. Even in these more complicated times, there are ways to preserve the benefits that physicianscientists provide to trainees, clinicians, hospitals, and ultimately to science and to patients. The student or trainee may learn more about future clinical science from a practicing physician-scientist than from a full-time clinician. Published reviews of the literature should be included in academic teaching rounds to enhance the instructive quality of rounds conducted by physician-scientists.

I suggest that most hands-on patient care and coverage of on-call schedules should be the primary responsibility of full-time clinicians. This should not preclude physician-scientists from having important roles in clinical settings. Rather, the idea that the physician-scientist should cover weekends and holidays to give full-time clinicians a break overlooks the benefits these individuals provide to trainees and fails to recognize the effort and energy required to run successful research programs. Particularly at risk are junior physician-scientists, whom I have seen on many occasions being yanked from the laboratory to cover for senior physicians. This can be disruptive to a fragile research career. Physician-scientists should not be asked to commit their time to providing breaks for full-time clinicians any more than equally busy clinicians should be asked to provide breaks for grant-writing, experiment-designing scientists.

Patients, clinicians, students, and researchers all lose when physician-scientists are discouraged from participating in clinical teaching and in patient care in the academic setting. Much lip service is paid to the need to translate progress in basic science to clinical benefit for patients, and the presence of physician-scientists on hospital rounds can improve this flow of knowledge. Physician-scientists should provide academic clinical leadership, since they have both the clinical depth and the academic foresight to move clinical programs into the future. I believe that our contributions serving in the clinics; teaching students, house staff, and clinical faculty; and acting as ambassadors from academic medicine have great value in academic health centers. Fellows and faculty need a regular infusion of teaching from active physician-scientists, whose creative ideas may challenge current clinical practices and lead to improved patient care. Ideally, physician-scientists can serve as role models through their dedication to using science to advance the practice of medicine.

\section{Andrew R. Marks Editor in Chief}

J. Clin. Invest. 117:2 (2007). doi:10.1172/ JCI31031.

1. Marks, A.R. 2005. How to support the basic sciences. J. Clin. Invest. 115:2. 